\title{
Um caso extremo do social \\ As sociedades dos prisioneiros nos campos de concentração nazistas
}

\author{
Joseph Jurt \\ Tradução de Julia Bussius \\ Revisão de Joseph Jurt e Leopoldo Waizbort
}

Existem inúmeros estudos sobre os campos de concentração durante o domínio nazista que se devem, em primeiro lugar, ao campo da História. No caso dessa instituição forçada, determinada por meio de uma extrema assimetria de poder, analisam-se, sobretudo, os assassinos, tanto suas premissas como o funcionamento do sistema. Nessa perspectiva, os prisioneiros aparecem como vítimas (passivas). Maja Suderland é uma das primeiras a analisar o mundo dos campos de trabalhos forçados nazistas de uma perspectiva sociológica, que tem no centro os prisioneiros ${ }^{1}$. Contrária à tese de que estes formavam uma massa amorfa, ela busca na base da literatura de testemunho, as evidências de que, mesmo sob condiçōes extremamente difíceis, os prisioneiros teriam construído uma sociabilidade, um sistema de relações sociais que se baseava em diferenças e semelhanças, a qual ela chama de "sociedade dos prisioneiros". Poderíamos supor que há necessariamente o desenvolvimento de relações sociais entre pessoas que precisam viver em contato permanente no interior de uma instituição, mesmo que o façam sob coerção. Porém, a autora entende como "sociabilidade" as relações sociais que se baseiem, ao menos em parte, na autodeterminação, ou simplesmente o fato de que as relações sociais, assim como as que existem no mundo "livre", de certo modo também continuam a existir ou são reconstruídas no sistema coercitivo. Essa tese já foi defendida pelo sociólogo de origem austríaca Paul Martin Neurath, que esteve detido nos campos de concentração Dachau e

1. Maja Suderland, Ein Extremfall des Sozialen: Die Häftlingsgesellschaft in den nationalsozialistischen Konzentrationslagern. Frankfurt am Main, Campus-Verlag, 2009. 
2. Esta e todas as indicações de páginas referem-se ao livro de Maja Suderland (N. E.).
Buchenwald, entre 1938 e 1939, por ser judeu e opositor do regime; ele emigrou para os Estados Unidos e lá analisou suas experiências nos campos de trabalhos forçados numa dissertação feita na Universidade de Colúmbia, com o título Social life in the german concentration camps Dachau and Buchenwald (1943), que só foi publicada em alemão postumamente, em 2005. Segundo Neurath, as "regras de conduta" nos campos forçados foram decerto adaptadas às circunstâncias, enquanto os basic concepts da sociedade "normal" continuavam a existir. Maja Suderland comprova essa tese com base numa extensa literatura de testemunho de ex-prisioneiros de diversos campos de concentração e extermínio até 1945, e analisa esse corpus com os instrumentos das teorias atuais do social.

Depois de precisar o objeto de estudo em questão, a autora apresenta a realidade dos campos de concentração nazistas numa introdução relativamente extensa (pp. 19-61). Ela comprova estar muito bem informada sobre o assunto e familiarizada com as pesquisas históricas mais recentes. Suderland realiza com êxito uma síntese impressionante do estado atual dos estudos sobre os campos forçados e, ao mesmo tempo, aponta as lacunas nas pesquisas sobre o assunto. Além disso, não é a cesura que ela ressalta fortemente, mas muito mais a continuidade do mundo dos campos com o mundo pré-concentracionário.

Foi decisivo para os nazistas o conceito ideológico de Volksgemeinschaft (comunidade do povo), que serviu para excluir minorias determinadas (e também construídas) considerando-as “inimigas internas". Os experimentos biológicos de raça dos médicos dos campos eram justificados como um pretenso serviço à "saúde do povo" e, mesmo antes de 1933, segundo a autora, eles existiam graças a uma "naturalização científica da medicina" (p. $50)^{2}$ e também não se realizavam num setor restrito. Alguns resultados dos “experimentos” também foram transmitidos pela medicina universitária.

O conceito de "prisão preventiva", que deveria legitimar a instalação dos campos forçados a partir de 1934, contradizia desde o início todas as normas constitucionais. A autora caracteriza o terror cotidiano contra os prisioneiros como um "estado de exceção permanente" (p. 47), que era determinado ao mesmo tempo por uma super-regularização e arbitrariedade, que acabavam deixando os internos numa insegurança total e, sobretudo, sob ameaça de vida. A autora comprova que os empregados dos campos eram, na maioria, oriundos da classe média (com profissões artesanais e comerciais), geralmente ameaçados pela decadência, e por isso - num mundo de orientação militar - procuravam reconhecimento social no interior da SS. A prática 
brutal contra os prisioneiros, tidos como a personificação do "inimigo interno", era um requisito, e tal prática foi classificada como demonstração de lealdade absoluta que, contudo, não excluía formas variadas de tratar os prisioneiros, segundo a autora. Os crimes cometidos em conjunto fortalecem os vínculos da comunidade de clã organizada por homens. Porém, não havia reflexôes sobre o terror praticado, de modo que se podiam fazer apenas declarações hipotéticas sobre os verdadeiros motivos dos criminosos. O número considerável de vigias - grosso modo, havia um guarda para cada prisioneiro -, que provinham da sociedade alemã e mantinham contato com esta através dos vários campos satélites, evidencia "a mescla da sociedade normal com a prática terrível nos campos” (p. 61).

Numa segunda parte muito exigente, intitulada "Movimentos sociológicos de busca” (pp. 63-163), os instrumentos teóricos sociológicos são examinados quanto à sua utilidade para a análise da ordem social distorcida da sociedade dos prisioneiros. Primeiramente a autora localiza suas proposições no interior do campo disciplinar. O corpus da pesquisa é construído com diversos testemunhos autobiográficos de prisioneiros - em língua alemã ou traduzidos para o alemão - que foram tratados como "construções de sentido" (p. 64). Pretendeu-se uma análise exploratória e metodologicamente qualitativa, e não uma análise representativa. $\mathrm{O}$ uso de fontes literárias como dados para uma análise sociológica é legitimado por meio de experiências análogas em Elias, Goffman e Bourdieu, porém ela se apoia especialmente no estudo sistemático Literatur als Soziologie (2003), de Helmut Kuzmics e Gerald Mozetiè, que ressalta a plasticidade do já reconhecido nos testemunhos literários, e enxerga as informações sobre valores e atitudes do social nas obras literárias com meios literários. A literatura é significativa como "complemento" (pp. 69-70) nos lugares em que não existia nenhum "dado" ou apenas dados deficientes. A literatura não assume simplesmente um status de "dado"; segundo o teórico da literatura Jurij Lotman, ela é uma modelagem secundária da realidade; aos olhos de Lukács, a literatura permite reconhecer o essencial além do fenômeno através da tipificação. Surpreende-nos que a autora, que se guia prioritariamente por Bourdieu, não recorra ao estudo As regras da arte, no qual ele atribui uma função cognitiva socioanalítica à literatura (de Flaubert).

M. Suderland limita seu enfoque a um interesse literário crítico, no qual a qualidade estética ficaria em primeiro plano; ela fala de literatura do holocausto e assim define a literatura de memória, no que tange ao conteúdo, como sendo "aquelas publicaçôes que, durante a perseguição nazista, elabo- 
raram o que foi vivido na forma de anotações, agendas e memórias com caráter de diário ou, ainda, literariamente” (pp. 71-72). Mesmo as tentativas de sistematização científica, como a dissertação de P. M. Neurath ou o relatório de E. Kogon, foram contabilizadas. Trata-se de um conceito muito amplo de literatura, que abrange o conjunto da elaboração escrita de experiências pessoais.

O interesse cognitivo também é delimitado em relação à história. Não se trata aqui da descrição completa de uma realidade com base em todas as fontes disponíveis, mas sim, nos termos da sociologia, de apoiar-se nos resultados enquanto uma "ciência de segunda ordem" (Simmel) e tentar apreender o típico por meio de uma análise das estruturas respaldada na teoria. A busca pela presença de características da estrutura social na população dos prisioneiros dos campos condiz com um interesse cognitivo sociológico genuíno.

Depois dessa localização disciplinar, é introduzida a ferramenta analítica com a qual o corpus da literatura de testemunho dos campos de concentração deverá ser examinada. "Sob a égide do conceito sociológico de Pierre Bourdieu [devem] ser implementados diferentes temas centrais teóricos a fim de obter um instrumento teórico de manipulação das questões de pesquisa aqui apresentadas acerca da sociedade nos campos de concentração" (p. 65).

Essa “orientação sociológica multidimensional” (p. 80) é justificada com referência a Bourdieu, que adota conscientemente conceitos de outras abordagens. A orientação por Bourdieu legitima-se por situar a lógica prática da ação no centro. As categorias de "espaço social" e habitus, especialmente, foram tomadas de Bourdieu. A autora reconhece que o próprio Bourdieu nunca pesquisou os campos de trabalhos forçados. Isso não surpreende, pois, para ele, num momento em que tudo fala de mudança social, a questão sobre as forças de perseverança da ordem social está em primeiro plano. Essa inércia é explicada pela categoria da violência simbólica, que não é consciente nem para os dominantes nem para os dominados e que, por essa razão, é tão eficaz. Diferente de Foucault, Bourdieu não vê o poder como um produto da disciplina ou do adestramento, mas sim como consequência da violência simbólica, que se impõe tão fortemente pelo fato de aqueles que a ela estão submetidos, cooperarem com sua manutenção. A violência física é menos eficiente, segundo Bourdieu, porque ela é percebida e incita assim à resistência. $\mathrm{O}$ trabalho de $\mathrm{M}$. Suderland documenta basicamente essa tese. 
Como Foucault concentrou-se, sobretudo, nas formas da violência física, a autora tem razão em também referir-se a ele. Com Foucault, ela constata a extrema "assimetria de forças" nos campos de trabalhos forçados e identifica a crueldade ritualizada que se dirige sobretudo aos corpos, como uma demonstração de poder pré-moderno. Porém, não estou certo de que a conclusão de Foucault sobre o pré-moderno - "através da punição ritual, a dignidade ferida do governante é restabelecida" (p. 150) - corresponde devidamente ao terror nazista, que tinha em vista sobretudo o extermínio, o "extermínio pelo trabalho", como a autora ressalta reiteradamente. Ela também vê no terror da SS, mais tarde, uma síntese de diversas formas de violência.

O conceito de "instituição total" de Goffman parece mais próximo da realidade dos campos de trabalhos forçados, pois ele pesquisa as estratégias de autopreservação possíveis (retração, negação, colonização, conversão) para os presos de tais instituições, que não conhecem nenhuma esfera privada.

Certamente também é justificada a referência à teoria da cultura de Zygmunt Bauman, que analisa justamente nos campos de trabalhos forçados a importância das atividades culturais como estratégia de sobrevivência.

Quanto à diferenciação social que se desenvolveu nos campos, sexo e classe constituem categorias importantes, mas também o conceito vago de etnia. A autora constata, então, que as três características que determinam a última categoria como pura incorporação da prática social - separação entre os conceitos de puro/impuro, de divisão hereditária do trabalho e da atribuição de uma posição firmemente delineada no interior da hierarquia social - correspondem exatamente às características das castas. Ela se apoia em Max Weber, que sustenta a tese de que o pensamento de castas é vigente também fora da Índia. Com o conceito de "casta", a autora encontrou uma categoria adequada para compreender os mecanismos de exclusão de judeus e dos ditos "ciganos", que se baseia em atribuiçôes; o conceito de "raça" é inapropriado, na verdade, porque sugere uma materialidade biológica (não existente).

A autora vê nos conceitos teóricos de Bourdieu - especialmente o conceito de habitus - a possibilidade de se "pensar indivíduo e sociedade em conjunto" (p. 92). A posição respectiva dos atores define os "esquemas de percepção, avaliação e ação" deles.

Porém, Suderland também faz referência a Louis Dumont e sua visão histórica da relação entre indivíduo e sociedade, que diferencia as sociedades holísticas pré-modernas das individualistas modernas. $\mathrm{Na}$ “ideologia ale- 
mã”, Dumont enxerga uma combinação de individualismo e holismo, e no nazismo um "pseudo-holismo", porque este liga o ideal de "comunidade do povo" com a ideia darwinista-social da luta de todos contra todos, portanto com a ideia de individualismo. Contudo, as noçôes de Dumont parecemme bastante esquemáticas e não compatíveis com a abordagem de Bourdieu. Este desconstrói a dicotomia clássica indivíduo/sociedade e, portanto, também a ideia de âmbitos puramente sociais ou puramente individuais como uma dicotomia pré-científica e política sem valor cognitivo. Uma teoria global da sociedade já pressupóe o que ela quer explicar - a sociedade como uma dimensão tendencialmente a-histórica. Por isso, para Bourdieu, o objeto de estudo não é a sociedade e, sim, o social. Segundo ele, o social está presente em duas formas: como história objetivada em forma de instituiçôes (campos) e na forma de uma história que se personificou (habitus). Os conceitos derivados da dicotomia indivíduo/sociedade - "individualismo", "coletivismo" -, na realidade, são conceitos polêmico-ideológicos e não conceitos descritivos.

Como representantes de uma "visão de mundo pseudo-holística", os nazistas, segundo a autora, atuavam com extrema brutalidade tanto contra os representantes de concepções holísticas (comunistas) como contra os protagonistas de uma ideologia individualista (artistas, por exemplo). Não estou seguro de que essa classificação dos prisioneiros de acordo com as categorias de Dumont faça muito sentido. Sem dúvida, era constante o empenho dos internos por uma "individualidade" como estratégia de defesa ao igualitarismo da SS. Esse empenho provavelmente não pode ser subsumido sob o conceito (valorativo) de individualismo.

Quando o crítico literário de direita Brunetière usa o "individualismo" para repreender os defensores da causa do oficial Dreyfus, condenado apesar de inocente, contra as razões de Estado, Durkheim o contesta dizendo que não se trata do enaltecimento de uma pessoa, e sim do indivíduo em geral, dos direitos humanos que constroem o fundamento da unidade moral do país. A busca da individualidade pelos prisioneiros origina-se no princípio básico de dignidade humana, como a autora sempre ressalta, portanto o princípio de igualdade (de direitos), que implica no princípio de liberdade e não apenas numa necessidade de hierarquização. $\mathrm{O}$ igualitarismo da SS, por outro lado, é uma igualdade forçada (por exemplo através do uniforme dos prisioneiros e das cabeças totalmente raspadas) que rouba a dignidade humana dos prisioneiros e se baseia na hierarquia entre seres humanos superiores e inferiores. 
A parte principal do estudo considera o "mundo social do campo de concentração nazista" (pp. 165-318) com base na análise do corpus da literatura de testemunho. A quintessência é expressada na citação de uma passagem da obra L'espèce humaine de Robert Antelm: "Quanto mais a SS pensa em nos tornar uma massa indiscriminada e irresponsável, algo que nós inegavelmente somos na aparência, tanto mais aguda se torna essa diferença. O homem do campo não é a neutralização dessa diferença. Pelo contrário, ele é efetivamente a sua realização" (p. 165). Esse diagnóstico é nuançado pela análise minuciosa dos testemunhos e analisado com os conceitos sociológicos apresentados.

Antes de tudo, são mostradas as muitas camadas da vida complexamente estruturada dos campos. Nos relatos, a chegada ao campo de concentração é vivida como um rompimento brusco com a vida anterior, como uma descontinuidade. São descritos os procedimentos de desumanização, nos quais qualquer autodeterminação é recusada, o despir-se, o roubo do nome próprio, a tatuagem do "estigma da escravidão" (Primo Levi). O aperto, a fome, as más condiçôes de higiene, evocam a imagem de um "mundo totalmente às avessas" (p. 210). Apesar dessas circunstâncias terríveis e dos grandes riscos, o desejo dos prisioneiros pelas açôes de autodeterminação continua sendo um objetivo importante e significa um elemento de continuidade. A autora verifica três níveis de sociabilidade que permitiram aos prisioneiros conquistar os "territórios do self" (Goffman).

O primeiro nível mencionado é o de uma "ordem militar", que se manifesta no uniforme dos prisioneiros, nos castigos públicos e na chamada dos números, servindo como demonstração de uma assimetria total de poder. Para os presos, às vezes o sistema militar já era familiar por experiência própria, o que lhes permitia orientar-se e por vezes até inventar nichos de estratégias próprias de solidariedade, pois era impossível sobreviver sem os outros. E apesar de o mais rígido "adestramento disciplinar" não poder ser evitado, "os prisioneiros encontraram meios e caminhos para encenar a solidariedade e a individualidade - e a si mesmos enquanto seres humanos" (p. 194).

Como segundo nível de sociabilidade, a autora identifica uma "zona nebulosa entre o desacato dos regulamentos e a tolerância das transgressões por parte dos guardas" (p. 200). Essa zona possibilitou a liberdade de movimento para uma economia secreta de comércio de trocas, da qual a própria SS fazia parte, e que seguia as leis gerais da economia. Além disso, atividades culturais, forçadas ou toleradas, que fortaleciam a identidade 
(música, teatro, cabaré), serviam como símbolos de continuidade com a vida anterior. Ruth Elias considerou uma noite de cabaré como a prova de que "nós, apesar da tirania de vocês, não perdemos nossas almas, [...] que, apesar de tudo, vocês não lograram esmagar nossa força de resistência” (p. 208).

Um terceiro nível especialmente oculto da sociabilidade, segundo a autora, apresenta a vida social dos prisioneiros, organizada detalhadamente. Uma série de atividades mentais de diversos tipos (escrita de poemas, relato de filmes, compor músicas, práticas religiosas, discussões científicas) conferiam um certo sentimento de autodeterminação e atestavam a tese de Zygmunt Bauman da "cultura como estratégia de vida" (p. 221). Os prisioneiros "se orientam para ser diferentes [...], para desviar-se da ideia de que todos estão igualmente ameaçados" (p. 218). A autora utiliza Goffman para descrever as estratégias de ação dos três níveis de sociabilidade como "formas moderadas" de "adaptação secundária" (p. 221).

Em todos os três níveis o habitus dos atores implicados contribui para a configuração das formas de atuação. A categoria de habitus de Bourdieu, adquirida na socialização da primeira infância e na escola, e age como "presença do passado", consegue explicar bem a continuidade (parcial) dos comportamentos. Parece-me decisivo que Bourdieu, contrário a suposiçôes precipitadas, não veja deterministicamente a ação do passado e, por isso, não fale de regras mas, sim, de estratégias, que os atores precisam planejar de diferentes maneiras, conforme a estrutura de cada campo.

O social específico da sociedade dos prisioneiros não se manifesta simplesmente nas já citadas estratégias individuais mas, também, nas afinidades sociais que se desenvolvem no universo do campo de concentração. Para apreender essa dimensão, Suderland muda da perspectiva microssociológica para a socioestrutural. As massas de prisioneiros, que à primeira vista parecem indiferenciadas, diferenciam-se segundo categorias distintas. Uma primeira classificação é elaborada pela SS, de acordo com a causa do aprisionamento, e esta é marcada por tipos diferentes de triângulos na roupa do prisioneiro. Criminosos que foram instrumentalizados para os propósitos nazistas (triângulo verde) constituem o grupo no topo dessa hierarquia. Em seguida vêm os prisioneiros políticos (triângulo vermelho), como os opositores do regime em si; depois os "antissociais", testemunhas de Jeová, ciganos e homossexuais, e, no último degrau, os prisioneiros judeus. Por meio dessa hierarquização e do consequente tratamento desigual, impedirse-ia uma solidariedade entre as classes. A autora também acentua forte- 
mente a tese da continuidade nesse trecho. A hierarquia dos campos reflete uma ordem da sociedade, ainda que seja uma "caricatura” (p. 228). A sociedade alemã já havia interiorizado antes o padrão de pensamento racista e biologista. Os ressentimentos antissemitas e homofóbicos teriam desdobrado seu efeito também no interior da sociedade dos prisioneiros. Cada prisioneiro, individualmente, podia se separar da categoria que lhe fora destinada ou então identificar-se com ela. Poderíamos questionar também a tese de continuidade. Se existiam os ressentimentos contra as ditas minorias, dificilmente existia uma hierarquia social na sociedade pré-concentracionária que colocava os criminosos no topo e os judeus em último lugar. Havia preconceito antissemita em vários países europeus. Mas o caminho sangrento que passou do preconceito contra um grupo à ideia de eliminação sistemática e física deste foi concebido apenas pelos nazistas e realizado nos campos de trabalhos forçados.

Portanto, na sociedade dos prisioneiros, as elites de presos construíram uma outra categoria social, que dispõe de poder e influência. $\mathrm{O}$ comportamento delas é assinalado pela autora com a categoria de Goffman de "colonização" e, nos casos extremos, a de "conversão" (à ideologia nazista). Através da existência de uma elite (favorecida) de prisioneiros, a sociedade do campo era dividida entre privilegiados e não-privilegiados. A posição deles entre a massa dos prisioneiros e os homens da SS também conduzia com frequência a um "habitus cindido" (p. 317).

No nível socioestrutural, não é pouca a importância da rigorosa separação entre os sexos. Suderland opera convincentemente a esse respeito com as teses desenvolvidas por Bourdieu em sua última obra, $A$ dominação masculina, na qual a relação entre os sexos é vista como uma relação de poder (interiorizada). As noçôes básicas de gênero - honra e masculinidade de um lado, e pudor e feminilidade de outro -, como aspectos de uma ordenação dos sexos recíproca e hierarquizada, também revelam sua eficácia nos campos de trabalhos forçados. A autora evidencia isso em uma série de exemplos marcantes como, por exemplo, a autopercepção das mulheres como percepção antecipada do outro, mesmo nos campos só de pessoas do mesmo sexo. Apoiada em Bourdieu, a autora mostra como os dominados utilizam as "armas dos mais fracos" (p. 305) e como o habitus feminino transformou-se em força no campo de concentração. Posto que a subnutrição extrema e as vestimentas iguais tornavam as diferenças físicas entre os sexos quase imperceptíveis, "a ênfase nos aspectos sociais da identidade sexual" (p. 318) parece ter sido ainda mais significativa. 
Na última parte, "Libido social", Maja Suderland conduz os resultados de sua pesquisa à uma síntese bem-sucedida. Contrária à ideia de que os prisioneiros dos campos de concentração não teriam construído qualquer sociedade sob essas restrições inumanas extremas, ela chega ao diagnóstico "de que as características de estruturação nos campos forçados eram tão virulentas como em qualquer sociedade normal” (p. 319). Quando a situação extrema representou um "fator de distorção social" (p. 321), então a "libido social" (Bourdieu) forçou a uma diferenciação social as pessoas. A ideia de dignidade humana teria ganhado prioridade absoluta. Os componentes essenciais da identidade social acabam sendo sexo, classe e atribuições étnicas. A partir disso, a autora pode divisar uma hierarquia dessas categorias. A afiliação de sexo estaria entre o topo das prioridades para os prisioneiros dos campos. Diante das condiçôes físicas extremas, teria sido muito importante para os prisioneiros "afirmar sua identidade sexual como um mínimo de identidade social, já que esta poderia ser entendida universalmente, independentemente de origem, status, língua e cultura da contrapartida equivalente" (p. 329).

Nos campos, o acordo de pertencimento a uma classe e a um ambiente teria sido mais difícil do que a diferenciação entre a ordem dos sexos aplicada binariamente. Os níveis de sociabilidade diferenciados microssociologicamente mostravam diversas intersecçôes no cotidiano do campo, que engendravam uma realidade social muito complexa e contraditória. A conclusão também depende da perspectiva:

De um lado, foi bem sucedida a estratégia da SS de transformar todos os presos em números administrados burocraticamente, que se matam por migalhas de pão; de outro lado, na mesma medida, era cada vez mais forte o desejo dessas pessoas, a tal ponto desumanizadas, de assegurar sua identidade enquanto exerciam a solidariedade e também cultivavam diferenças significativas e nuances, que remetiam ao seu modo de vida anterior (p. 335).

Maja Suderland apresentou um trabalho significativo. Ela escolheu uma temática central: "o acontecimento mais importante do século XX" (Michel Pateau) e investigou a continuidade das estruturas sociais sob as condições extremas dos campos de trabalhos forçados nazistas - uma dimensão quase não pesquisada, que deve entrar em pauta na sociologia. 
Ela concebeu um instrumental teórico muito preciso para sua pesquisa, que lhe possibilitou chegar a novas conclusões. Ela poderia ter dispensado apenas os conceitos de Louis Dumont, que não fariam falta. Porém, a grande precisão analítica de modo algum impede um tom adequado, condizente a uma realidade quase incompreensível, sustentada por uma empatia com os presos, que não são simplesmente vistos como vítimas e, sim, como atores sociais. Se levarmos a sério o ponto de vista desses atores, os elementos de continuidade com o mundo pré-concentracionário ganharão nova importância, ao passo que uma perspectiva de fora nos deixa tentados a enxergar apenas os elementos de descontinuidade, a quebra com o mundo anterior.

\section{Resumo}

Um caso extremo do social: as sociedades dos prisioneiros nos campos de concentração nazistas

Após sobretudo os historiadores terem investigado os campos de concentração no espaço de dominação nacional-socialista, Maja Suderland oferece uma das primeiras análises sociológicas da comunidade de prisioneiros dos campos. Contra a tese de que os prisioneiros formariam uma massa amorfa, ela comprova, baseada na literatura de testemunho, que os prisioneiros construíram um sistema diferenciado de relações sociais. A análise orienta-se pelas concepções teóricas de Bourdieu, nomeadamente seu conceito de habitus, pelo conceito de poder de Foucault, pela concepção de "instituição total" de Goffman, pela teoria da cultura de Zygmund Bauman e pelo esboço histórico de Louis Dumont acerca das relações de indivíduo e sociedade. Com o auxílio dessas categorias, a autora destila três planos da socialidade na literatura de testemunho, que possibilitaram aos prisioneiros conquistar "territórios do self": o plano da ordem militar, o plano econômico da troca e o plano cultural do cotidiano. No plano da estrutura social, as categorias de gênero, classe e etnia revelaram-se de importância decisiva para a manutenção da identidade social dos prisioneiros. Se a situação extrema representava também um fator de deformação social, a autora demonstra que nos campos de concentração existiam também características estruturais similares às da sociedade "normal". A prioridade máxima para os prisioneiros era a ideia de dignidade humana. No estudo em pauta, os prisioneiros são vistos não somente como vítimas, mas também como atores sociais. Os elementos de continuidade, e não simplesmente os elementos de ruptura com o mundo anterior ao campo de concentração, obtêm dessa perspectiva um novo significado.

Palavras-chave: Campo de concentração; Ordem social; Instituição total; Bourdieu. 


\section{Abstract}

An extreme social case: prisoner societies in nazi concentration camps

After all the historical investigation into the concentration camps from the perspective of national socialist domination, Maja Sunderland offers one of the first sociological analyses of the communities formed by camp prisoners. Countering the thesis that the prisoners were basically an amorphous mass, she draws upon first-hand accounts in the literature to show how they actually devised a special system of social relations. The analysis is oriented by the theoretical concepts of Bourdieu, particularly his notion of habitus; by Foucault's concept of power; Goffman's 'total institution' concept; the culture theory of Zygmund Bauman and Louis Dumont's historical outline of the relationship between the individual and society. With the help of these categories, the author distills from the first-hand accounts three planes of sociality that enabled them to demark "territories of the self", namely: military order; economic exchange; and everyday cultural exchange. On the level of social structure, the categories of gender, class and ethnicity proved decisive in maintaining the social identity of the prisoners. While this extreme situation represented a social deformation, the author shows that structures akin to those of "normal" society also managed to take hold, even in the concentration camps. For the prisoners, the idea of human dignity was of the utmost importance. In the present study, the prisoners are not seen merely as victims, but as social agents. The elements of continuity, as opposed to those of rupture with the pre-camp world, acquire new meaning under this perspective. Keywords: Concentration camp; Social order; Total institution; Bourdieu.

Texto recebido e aprovado em $6 / 10 / 2009$. Joseph Jurt, Romanisches Seminar, AlbertLudwigs-Universität Freiburg, Alemanha. 